\title{
Intraposition and Formosan Adverbial Heads
}

\author{
Arthur Holmer \\ University of Lund
}

\section{Background}

From its inception, the adoption of Kayne's (1994) Antisymmetry hypothesis has posed important challenges for the analysis of VOS languages. The initial problems (how to derive the VOS word order itself) were successfully dealt with by among others Pearson (1998), who proposed that VOS order be derived by raising the predicate past subject position. In Massam (2000) predicate raising is analysed as VP raising to SpecTP as the result of a [+pred] EPP feature in (some) verb-initial languages (1a), contrasting with a [+D] EPP feature in SVO languages $(\mathrm{lb})$.

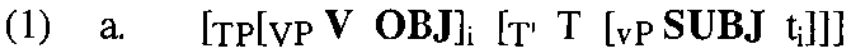 \\ b. [TP $\mathbf{S U B J} \mathbf{J}_{\mathbf{i}}\left[\mathrm{T}^{\prime} \mathrm{T}\left[\mathrm{vP} \mathrm{t}_{\mathrm{i}}\left[\mathrm{v}^{\prime} \mathrm{v}[\mathrm{VP} \mathbf{V} \mathbf{O B J}]\right]\right]\right]$}

One problem with this approach is that it does not account for the extremely head-initial nature of VOS languages in general. VOS languages do not only have VOS word order: at some descriptive level, they seem to require a structure which is consistently Head-Complement-Specifier, an option disallowed by the Antisymmetry hypothesis. In fact, as Aldridge (2002) and Holmer (2004) have shown, recursive instances of predicate raising are required simply to allow for the order of the arguments, verbal heads and post-subject particles. The situation is further exacerbated if we include the ordering of adverbs in VOS languages, this issue being the topic of the present paper.

In Cinque (1997) a universal hierarchical ordering of adverbs is suggested, based on a wide range of languages. A subset of this hierarchy, quoted from Rackowski \& Travis (2000:121) is shown in (2).

(2)

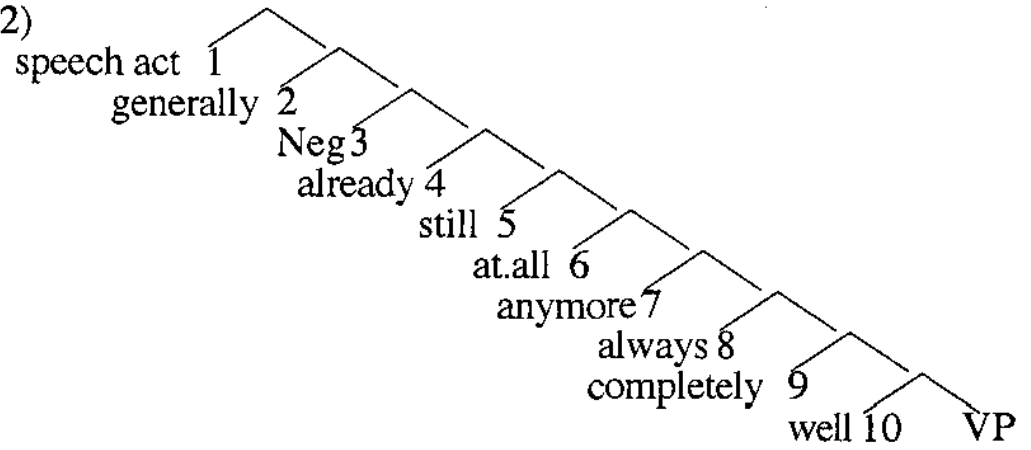

Given Antisymmetry, the hierarchical ordering suggested by Cinque should, ceteris paribus, be mirrored by a universal linear ordering. The facts in the VOS language Malagasy, the topic of Rackowski \& Travis (2000), are unexpected in this light. Given the numbering in (2), the linear order found in Malagasy is that in (3).

(3) 2 - 3 - 4 - 5 - VERB - $10-9-8-7-6-1$ - SUBJ 
Basically, the Malagasy data conforms linearly to the Cinque hierarchy for preverbal adverbs, whereas the reverse order holds for all postverbal adverbs. This fact leads Rackowski \& Travis (2000) to posit a generalized system of predicate raising termed intraposition, where a large portion of the structure is rolled up, as it were, and surfaces in reversed linear order to the right of VP (4).

(4)
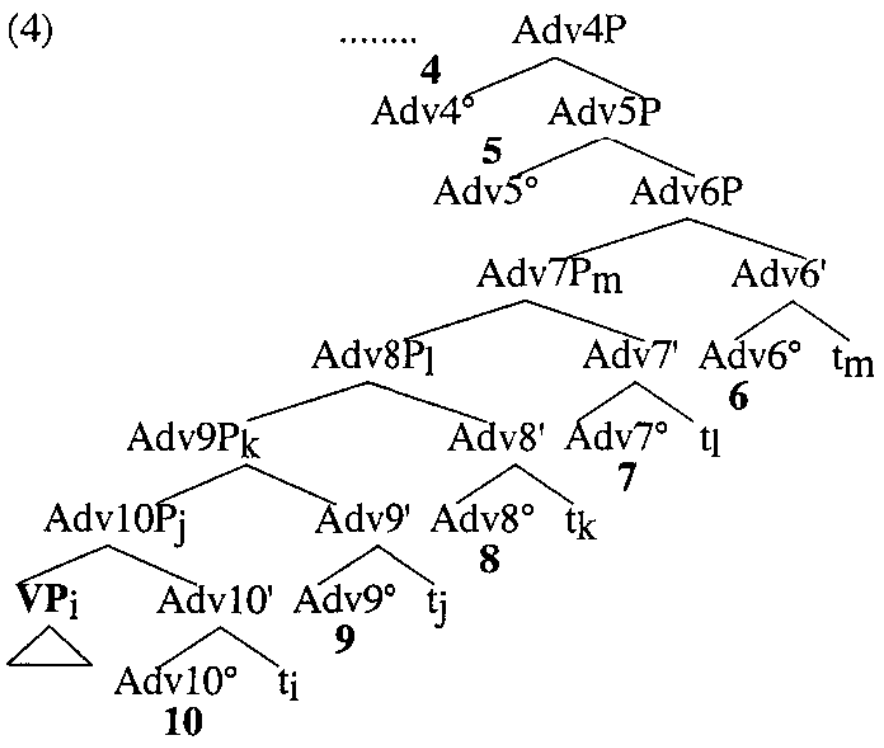

An obvious question at this stage would concern the motivation for movement Rackowski \& Travis' suggestion is that predicate raising is not a feature of a single head (such as $T$ ) but rather of every level which is an expansion of VP (e.g. AspP, TP, various AdvP's), possibly extending to the clause as a whole. This would be the defining feature of a predicate raising language as opposed to an argument raising language (cf. Pearson 1998). In a predicate raising language, a head $\mathrm{X}$ will trigger raising of its complement to SpecXP (5).

\section{(5) $\left[X P Y P_{i}\left[X^{\prime} X^{\circ} t_{i}\right]\right]$}

Viewed in this light, the predicate raising mechanism as such is not a problem. Rather, the more serious question would instead seem to be what prevents the process from continuing throughout the whole structure: why are not all Malagasy adverbs postverbal with reverse Cinque order?

The predicate raising mechanism illustrated in (4) and (5) operates around heads, and this leads Rackowski \& Travis (2000:122) to suggest that preverbal adverbs are not heads, but are phrasal, and are located in the Specifier positions themselves. The crucial consequence of this is that the specifier position is blocked, thus effectively preventing further predicate raising. Given that the entire analysis crucially rests on the assumption that certain elements are heads and others are phrases, it would be an advantage if some independent evidence for the $\mathrm{X}$ / XP status of the elements could be unearthed. Unfortunately, such evidence is hard to come by in Malagasy. However, other Austronesian languages with similar word order patterns do display rather robust evidence for the head status of certain elements. One such language in the Formosan language Seediq. 


\section{Seediq}

\subsection{Headhood in Seediq}

Seediq is an Atayalic language spoken in the area between Puli in central Taiwan and Hualien on the Pacific coast. It is a classic example of a VOS language (6a), although this is sometimes obscured by various other facts, including emphatic subject fronting (6b), the typical Austronesian voice (or "focus") system (6c) and pronominal cliticization (6d).

(6)

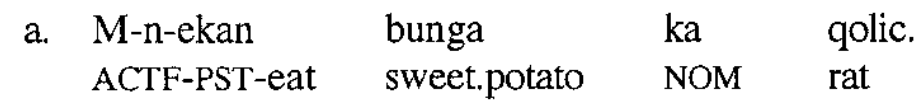 'The rat ate sweet potatoes.'
b. Pawan (ka) m-n-imah sino.
Pawan NOM ACTF-PST-drink wine
'Pawan (was the one who) drank wine.'
c. P-n-uq-an qolic ka bunga. -PST-eat-LOCF rat NOM sweet.potato
'A rat ate the sweet potato.'
d. M-n-imah=ku sino kiya. ACTF-PST-drink=1SG.NOM wine that 'I drank that wine.'

Most crucially for the present discussion, Seediq also has a similar patterning when it comes to adverb ordering. Relevant examples, with numbering of adverb types as in (2) or (3), are given in (7a-e).

'(They) don't just take clothes which (other) people have thrown.'
c. M-uuyas ruru kiya klaali heya.
ACTF-sing stream there always 3SG.NOM
V $\quad 8 \quad$ S

'It (the frog) always sings by the stream.'

d. Ini=ku k-qeni na

NEG $=1$ SG.NOM CONNEG-thirsty NA

$\begin{array}{lll}3 & \mathbf{5} & \mathbf{5}\end{array}$

'I am not thirsty (yet).'

e. m-usa m-ekan seedaq kiya gaga cghuun kiya di $\mathbf{s i}^{1}$ ACTF-go ACTF-eat person that be hang there DI SA $\begin{array}{lll}V & 4 & 1\end{array}$

'they (the crows) go and eat the hanged person, so it is said' 
The pattern for adverbs in Seediq can be summarized as in (8). The basic picture is similar to that in Malagasy: preverbal adverbs appear in Cinque order, and postverbal adverbs appear in reverse Cinque order. One noticeable difference between Seediq and Malagasy is that all postverbal adverbs are presubject in Malagasy, whereas some of them are postsubject in Seediq, the reverse Cinque ordering still being the same as in Malagasy, however. The difference between Seediq and Malagasy could be expressed in intraposition terms such that the raised predicate in Malagasy never contains the subject, whereas in Seediq the subject may be included in the raised structure.

\section{(8) 1 - 3 - 6 - 10 - VERB - 8 - SUBJ - 5/4 - 1}

From the above, it is clear that there is no a priori reason to assume that adverb ordering is derived differently in Seediq and Malagasy - rather, we expect Rackowski \& Travis' analysis to carry over directly to Seediq. For this reason, the head-status tests which Seediq syntax can offer us are directly relevant to the Rackowski \& Travis analysis.

In Seediq, pronominal clitics attach to the highest head in the clause. This can be a subordinator (9a) or an interrogative particle (9b), but it can also be a T/A-marker (9c), a negator (9d) or the main verb (9e).

(9) a. Netun=su m-imah sino, bsukan=su dhenu. if-2SG.NOM ACTF-drink wine drunk-2SG.NOM consequently 'If you drink wine you will get drunk.'
b. $\mathbf{Y e}=\mathrm{su}$ m-n-imah sino ciga? INTERR-2SG.NOM ACTF-PST-drink wine yesterday 'Did you drink wine yesterday?'
c. Wada $=$ mu qta-un ka huling=su. PST=1SG.GEN See-PATF NOM dog=2SG.GEN 'I saw your dog.'
d. Ini=ku kela r-m-engo kari seediq. NEG=1SG.NOM know.ACTF.CONNEG -ACTF-talk language person 'I can't speak Seediq.'
e. $M-n-e k a n=k u \quad$ ido ciga. ACTF-PST-eat $=1 \mathrm{SG} . \mathrm{NOM}$ rice yesterday
'I ate rice yesterday.'

It is important to note that, in contrast to Tagalog, the cliticization process does not involve 2 nd position Wackernagel clitics. Rather, cliticization is a syntactic process which is sensitive to the status of the host. Cliticization may not take place to conjunctions (10a), nor to wh-phrases (10b).

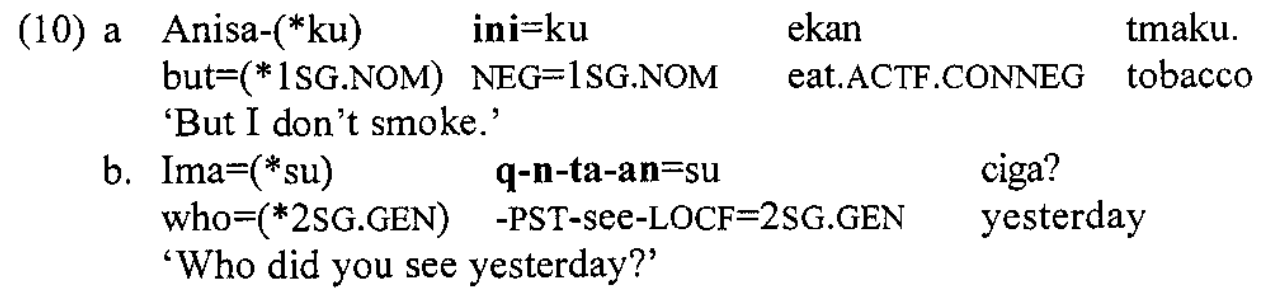


On the other hand, a wh-word may attract clitics if and only if it is a syntactic head, e.g. the wh-verb hmuwa / hwaun 'to do what' (11a). Further, no phrasal adverbials of any kind may attract clitics (11b). It is crucial to note that, in contemporary Seediq, the phrasal adverb ini huwa 'it is $O \mathrm{~K}^{\prime}$ ' is not clauseexternal, as evidenced from the fact that the clitic can climb past it to an interrogative particle $(11 \mathrm{c})^{2}$.
a. Hwa-un=ta
seediq so nii me-eguy?
do.what-PATF=1PL.INCL person like this ACTF-steal 'What shall we do with a thief like this?'
b. Ini-(*su) huwa-(*su) m-ekan=su NEG how.ACTF.CONNEG ACTF-eat=2SG.NOM tobacco here 'It's OK if you smoke here.'
c. $Y \mathrm{e}=\mathrm{ku}$ ini huwa m-ekan tmaku? INTERR=1SG.NOM NEG how.ACTF.CONNEG ACTF-eat tobacco 'Is it OK if I smoke?'

Seediq also displays clear morphological evidence for head-status, e.g. the behaviour of connegatives. The rules governing the use of the connegative are as follows: if there are two verbs present, such as in a control construction, both are realized in normal affirmative morphology (12a). If the clause is negated, the superordinate verb must be realized with connegative morphology $(12 b, c)$, which is formally identical, for all voices, with the imperative. However, any verb subordinate to the negated verb may not be realized in connegative form, but must be realized in default morphology (12d). These facts can be summarized graphically as in (12e).
ACTF-know=1SG.NOM
'I can speak Seediq.'
a. $\mathrm{m}-\mathrm{kela}=\mathrm{ku}$
r-m-engo
kari
seediq -ACTF-talk
language
person
b. ini $=\mathrm{ku}$
kela
r-m-engo kari seediq
NEG=1SG.NOM ACTF.CONNEG.know -ACTF-talk language person
'I can't speak Seediq.'
c. ${ }^{*}$ ini $=\mathrm{ku}$ m-kela r-m-engo kari seediq NEG=1SG.NOM ACTF-know -ACTF-talk language person
d. $*$ ini $=\mathrm{ku}$ kela rengo kari seediq
NEG=1SG.NOM ACTF.CONNEG.know ACTF.CONNEG.talk Seediq
e. ini + CONNEG + not CONNEG

The fact that a verb can be assigned connegative morphology by the negation, and that this morphology can be blocked by an intervening verb, is most easily captured under the assumption that all elements involved in this interaction are heads.

Another piece of evidence concerns the T/A markers, which occur in complementary distribution with the corresponding morphology on the verb. For example, past tense in perfective aspect can be expressed with the particle wada (13a) or with overt morphology on the verb (13b), but not with both (13c). If the particle wada is used, the main verb must be realized in a form unmarked for T/A (cf. 13a). 
(13)
a. wada $=m u$ qta-un $\mathrm{ka}$ sapah=su PST=1SG.GEN see-PATF NOM house=2SG.GEN 'I saw your house.'
b. $\mathrm{q}-\mathrm{n}-\mathrm{ta}-\mathrm{an}=\mathrm{mu}$ -PST-see-LOCF=1SG.GEN NOM ka sapah=su house $=2$ SG.GEN 'I saw your house.'
c. * wada=mu q-n-ta-an ka sapah=su $\mathbf{P S T}=1$ SG.GEN -PST-see-LOCF NOM house=2SG.GEN

The same occurs with various directional preverbs. If the clause occurs in a certain distinctive voice / "focus" form, this can be realized on the directional preverb, if one is present (14a), or on the main verb, as long as no directional preverb is present $(14 b)$, but never on both $(14 c)$. If the directional preverb is used, the main verb must be realized in morphology which is unmarked for voice I "focus", i.e. actor focus (ActF), cf (14a).
a. yah-un m-ekan qolic ka bunga come-PATF ACTF-eat rat NOM sweet.potato
'Rats will come and eat the sweet potatoes.'
$\begin{array}{lll}\text { b. puq-un qolic } & \mathrm{ka} & \text { bunga } \\ \text { eat-PATF rat } & \text { NOM } & \text { sweet.potato }\end{array}$
'Rats will eat the sweet potatoes.'
$\begin{array}{lllll}\text { c. }{ }^{*} \text { yah-un puq-un } & \text { qolic } & \text { ka } & \text { bunga } \\ \text { come-PATF } & \text { eat-PATF } & \text { rat } & \text { NOM } & \text { sweet.potato }\end{array}$

These features are all typical of the assumed behaviour of heads in syntactic structure. They also hold for a substantial set of elements which have meanings typical of manner adverbials. This class of adverbials display the same kind of behaviour as directional preverbs, in that they can realize the voice morphology which semantically corresponds to the main verb of the clause $(15 \mathrm{a}, \mathrm{b})$, at the same time preventing the same morphology from being realized on the main verb (15c).
a. tte-un=daha $\quad$ t-m-ekan ka macu to.pieces-PATF $=3$ PL.GEN $\quad$-ACTF-pound NOM millet 'They pound the millet to pieces.'
b. $\underline{\text { kan-un}}=$ daha ka macu pound-PATF=3PL.GEN NOM millet 'They pound the millet.'
c. *tte-un=daha tkan-un ka macu to. pieces-PATF=3PL.GEN pound-PATF NOM millet

Some representative examples of the distribution of voice morphology are given in (16a-d). Example (16d) is particularly illustrative, in that it shows the same verb tmuting / tting un 'beat' occurring in two constructions, providing a nearminimal pair. 
(16) a. skret-an=daha m-ekuy quwaq salo tight-LOCF $=3$ PL.GEN ACTF-tie mouth pot 'They tie the mouth of the pot tightly.'
b. bleq-un=daha g-m-emuk well-PATF=3PL.GEN $\quad$-ACTF-cover
'They cover it well...'
c. gguy-un=misu s-m-neru secretly-PATF $=1 \mathrm{SG}->2 \mathrm{SG} \quad$-ACTF-tell
'I'll startle you.'
d. tting-un=daha qhuni ka qmegi, beat-PATF=3PL.GEN tree NOM soapwort, nme-un=daha t-m-uting... to.powder-PATF=3PL.GEN -ACTF-beat

'They beat the soapwort berries off a tree and pound them to powder.'

Examples (17a-c) show that it is the adverbial head, not the main verb, which receives connegative morphology when combined with the negator ini. Likewise, it is the adverbial head, not the main verb, which is realized in imperative if the entire utterance is a command (17d).
a. ini=daha
mhmet-i
s-m-ipaq
sa
NEG $=3 P L$. GEN
needlessly-PATF.CONNEG -ACTF-kill
QUOT
'It is said that they don't kill them (100-pacer snakes) needlessly.'
b. ini burux m-ekan ka seediq cbeyo
NEG alone.CONNEG ACTF-eat NOM person long.ago
'The people of old didn't eat alone.'
c. ini=daha
trmex-i
NEG $=3$ PL.GEN on.its.own-PATF.CONNEG ACTF-eat
'They don't eat it (the chili) on its own... (because it's so hot).'
d. k-tengi hari m-ekan!
IMP-full a.bit ACTF-eat
'Eat some more! / Eat until you are more full.'

Most elements which occupy this position convey meanings typically corresponding to adverbs of manner. However, this group also contains a handful of adverbs referring to frequency and duration (18a,b).
a. Ini=daha kntte-i
NEG $=3$ PL.GEN often-PATF.CONNEG pcnga-un=daha
sometimes-PATF=3PL.GEN
m-ekan beras baso,
m-ekan
ACTF-eat
'They don't eat baso grain often, they eat it occasionally.'
b. ini=daha
qbsyaq-i
pure
heya
NEG $=3$ PL.GEN
long.time-PATF.CONNEG
(ACTF).cook 3SG.NOM
'they don't cook it (taro) too long.'

At least for the above sets of manner adverbs, it is difficult to conclude that they can be anything other than heads. Other preverbal elements with adverbial meanings also seem to display head characteristics, although less clearly, due to 
the fact that they are located structurally higher than the most relevant types of morphology. One clear instance is the negator ini, which triggers connegative morphology and attracts clitics (19a). Another element which attracts clitics is the particle tena 'already' which is located preceding the tensed verb, and which for this reason is not involved in any morphological processes typical to verbs (19b). The status of tena as a head can only be surmised from the fact that it attracts clitics, which may be subject to debate, although it has been argued here that clitic attraction in Seediq is an exclusive property of heads. At least one preverbal element is clearly not a head according to the above criteria, namely $b a$ 'indeed', given that it can intervene linearly between the negator ini and the main verb without blocking the assignation of connegative morphology (19c).
a. Ini=mu
qta-i
$\mathrm{NEG}=3$ SG.GEN
see-PATF.CONNEG
ka
'I didn't see that snake.'
b. Tena=ku m-n-ekan ido.
already $=1$ SG.NOM ACTF-PST-eat rice
quyu
kiya
'I've already eaten.'
c. Kiya ini=daha
thus NEG=3PL.GEN indeed touch-PATF.CONNEG
ka seedaq m-n-cghuun.
NOM person ACTF-PST-hang
'they certainly don't touch people who have hanged themselves.'

\subsection{The analysis}

The conclusion we can draw from the above is that preverbal adverbial meanings in Seediq can be expressed by both heads and non-heads. It follows that the Rackowski \& Travis' (2000) account of what prevents predicate raising past preverbal adverbs does not carry over to Seediq. In fact, given that head status evidence is visible in Seediq but not in Malagasy, it could be argued that the Seediq evidence weakens Rackowski \& Travis' arguments for Malagasy as well. Therefore, at least for Seediq, an alternative analysis accounting for the presence vs. absence of predicate raising must be found.

One possibility might be to posit that preverbal adverbs are heads and postverbal adverbs are phrases, in analogy with Shlonsky's (2003) analysis of Hebrew NP's. However, one problem with this view is that postverbal adverbs (in particular final particles) can not be expanded (a behaviour otherwise typical of phrasal elements, cf. the discussion in Holmer 2004). An illustrative example of the expansion argument concerns negation in English and German. In English, not is a head, since it triggers do-insertion (in certain versions of the theory, cf. Ouhalla 1991, by virtue of blocking verb movement), whereas German nicht is phrasal (presumably in the Specifier of NegP) and does not block verb movement. English not cannot be expanded (in its canonical position and with its canonical behaviour) into complex negations such as 'not at all' or 'never', whereas German nicht can easily be replaced by überhaupt nicht 'not at all', nie im Leben 'never ever (lit. never in one's life)' and many other types of complex negations. In cases of doubt, I assume here that the impossibility of phrasal expansion can serve as evidence for head status.

Under the assumption that postverbal adverbs (including final particles) are 
also heads, another problem arises, namely how it can be that these heads, if they are heads, do not block head movement according to the Head Movement Constraint. There is plausible evidence for head movement $(\mathrm{V}-\mathrm{C})$ in Seediq, given that clitics, which are crucially not 2 nd position clitics, can attach to either subordinators (20a) and verbs (20b), depending on which is first. Here the default assumption would be that they attach to a single discrete head (i.e. $\mathrm{C}^{\circ}$ ) and that head movement ensures that $\mathrm{C}^{\circ}$ which is not filled by a subordinator is lexically filled by movement instead (cf. Holmberg \& Platzack's (1995) analysis of $\mathrm{V} 2$ languages).

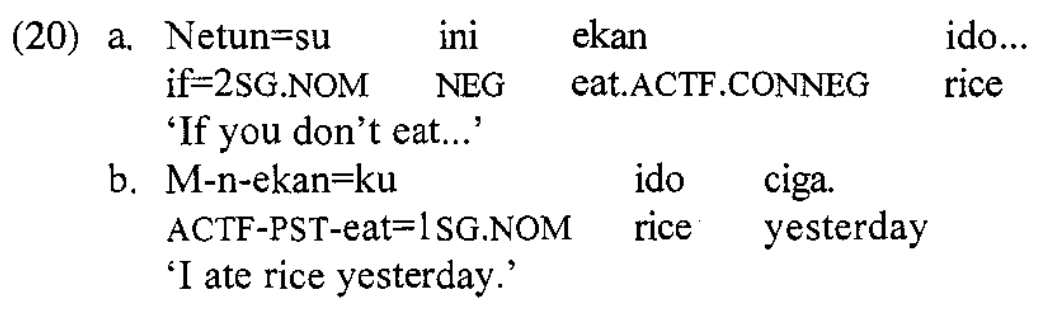

If we discount cliticization, other evidence of head movement is hard to come by, given the extremely head-initial nature of the language. One possible case might be the behaviour of $b a$ 'indeed'. In (21a), $b a$ is located to the left of the manner adverb, whereas in (21b) is is located to the right of the manner adverb. These two examples can be captured under a head movement analysis assuming that $b a$ is not a head and that the adverb in (21b) moves past it because the position to the left of $b a$ is not occupied by any other element.
(21) a. ini ba mhmet-i
NEG indeed at.random-PATF.CONNEG ACTF-take cloth 'they certainly don't just take clothes ...'
b. blequn=daha ba s-m-netun ma rees-un=daha well=3PL.GEN indeed -ACTF-follow and bury-PATF=3PL.GEN 'they observe (the law) meticulously and bury them'

Even if overt verb movement could be shown not to occur, the relation between the T/A markers and the overt morphology of the verb, namely that they cannot cooccur (22a-c), suggest that they are checked in the same syntactic position, if not overtly, then at least covertly. The intervening postverbal adverbs do not block this covert checking relation either. ${ }^{3}$
(22) a. wada $=$ mu qta-un ka huling

For the reasons outlined above, the relation between head-raising and possible intervening heads seems to be a serious problem which must be addressed. 
Apparent violations of the Head Movement Constraint are not rare among the world's languages. Possibly the most publicized phenomenon of this type is Long Head Movement (cf. Borsley et al. 1996). Carnie, Harley \& Pyatt (2000) discuss similar facts in Old Irish and suggest, following Borsley et al. (1996), that heads, in analogy with phrasal positions, can also be classified in terms of the $\mathrm{A} / \mathrm{A}^{\prime}$ distinction. Just as a filled $\mathrm{A}$ position does not block $\mathrm{A}^{\prime}$-movement of a phrase, neither does a filled $\mathrm{A}$ head position block movement to an $\mathrm{A}^{\prime}$-head position.

In analogy with this distinction, we suggest that heads in Seediq can be of two classes, one class which is involved in head movement and which is typically associated with left-marginal or postverbal position, and one class which triggers predicate raising, which is in no way involved in head raising, and which is typically associated with postverbal position. Whether or this distinction is analogous to the A / A' distinction as proposed by Carnie, Harley \& Pratt (2000) is an open question. Certainly, neither can be derived straightforwardly from the other. For instance, neither of the two types of head in Seediq is particularly or exclusively connected with $\mathrm{C}^{\circ}-$ in fact, conditional subordination itself can be expressed either by the clause-initial head netun 'if' which blocks head movement $(23 \mathrm{a}, \mathrm{b})$ or by the final particle $d o$ 'if' (23c).
a. $\mathrm{m}$-imah=su sino klaali
ACTF-drink=2SG.NOM wine always
'You drink wine all the time.'
b. netun=su m-imah $\left.*^{*}=\mathrm{su}\right)$
if $=2$ SG.NOM ACTF-drink $(*=2$ SG.GEN $)$
sino klaali...
wine always
'If you drink wine all the time...'
c. $m$-imah=su sino klaali do...
ACTF-drink=2SG.NOM wine always COND
'If you drink wine all the time...'

At this stage, we shall refer to the two types of head as X-heads and Y-heads respectively, deferring to future research the issue of whether this distinction has any common denominator with the A / $\mathrm{A}^{\prime}$-distinction. The properties of the two types of heads are given in (24).

(24) X heads: undergo / block head-raising

Y heads: irrelevant for head-raising; trigger PRED-raising

Given that $\mathrm{X}$ heads are involved in head raising, it is naturally only $\mathrm{X}$-heads which will be able to host typical verbal morphology. Thus a further property of $\mathrm{X}$-heads crystallizes, namely that they can be part of the verbal system of morphology (behaving like prototypical heads in the sense we are used to from European languages), something which never occurs for $\mathrm{Y}$-heads. ${ }^{4}$

In Holmer (2004) the distinction between $\mathrm{X}$-heads and $\mathrm{Y}$-heads was harnessed to account for the fact that final particles ( $\mathrm{Y}$-heads) do not block verb movement. This analysis can be extended to account for the ordering of adverbs in Seediq as well. If we follow Rackowski \& Travis (2000) in analysing postverbal adverbs as heads, the distinction between preverbal and postverbal heads can easily be reduced to a distinction between X-heads (preverbal) and Y- 
heads (postverbal). Final particles are simply a special instance of Y-heads, hierarchically so high in the structure that the raised predicate includes the position containing the grammatical subject, whereas postverbal (but pre-subject) adverbs are located lower in the structure (as we indeed would expect, given their relation to the Cinque hierarchy), so that the raised predicate does not include the subject.

The proposed distinction thus allows us to apply Rackowski \& Travis' (2000) predicate raising analysis to Seediq postverbal adverbs, and to reconcile this analysis with morphological evidence from preverbal adverbs. In the narrowest sense, it only claims to account for data in Seediq (and other languages where manner adverbs are realized as verbs). However, the same analysis can be carried over to Malagasy and other VOS languages with similar adverb ordering, under the assumption that the distinction between $\mathrm{X}$-heads and $\mathrm{Y}$-heads can be maintained without morphological desinences.

\section{Geographical and genetic distribution}

One question to be asked at this stage is how widely spread this phenomenon really is: where else, outside Seediq do we find morphological head evidence for preverbal adverbs? In the closest relatives of Seediq, namely the other Atayalic languages in Taiwan, Squliq Atayal and C'uli Atayal, we find much the same phenomenon, behaving exactly as in Seediq. Examples (25a-c) illustrate this for Squliq Atayal, and examples (25d-f) illustrate it for C'uli Atayal.

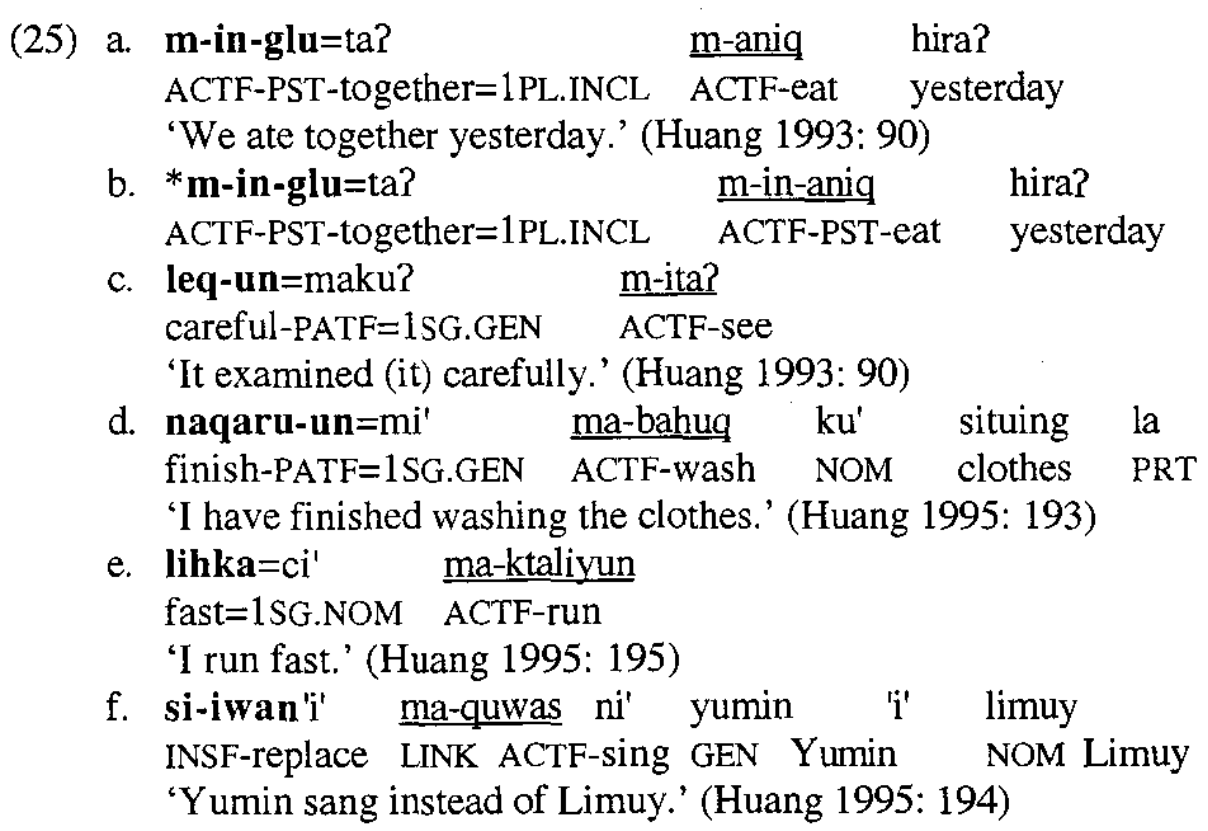

A similar pattern is found in the Paiwanic language Bunun, also spoken in Taiwan (Jeng 1977), as shown in examples (26a, b).

(26) a. qasmav-un ?ista ma-tas?i? palangan diligent-PATF 3SG.GEN ACTF-make rattan-basket

'He is diligent making rattan baskets.' (Jeng 1977:210) 

b. ma-qasmav ?aipa?
ACTF-diligent 3SG.NOM ACTF-make rattan-basket
'He is diligent making rattan baskets.' (Jeng 1977:205)

In the third Formosan group, Tsouic, similar facts obtain, albeit with an important difference. We have noted that in the Atayalic languages and (at least some) Paiwanic languages verbal morphology on the adverb precludes morphological distinctions on the main verb, which is instead realized in default ActF. In Tsou, on the other hand, both the adverb and the verb display the focus morphology corresponding to the whole clause. Thus, the verbal morphology on the adverb and the main verb agrees, although the full distinction is only realized on the main verb, the adverb only realizing a defective distinction between ActF and non-ActF (glossed here as UNDF 'Undergoer Focus', following the source of the examples, Szakos 1994). Relevant examples are given in $(27 a, b)$.
a. $\varnothing$-o-si-cu aha'-va eh-tothom-neni
UNDF-PR-3-PERF sudden-UNDF against-fight-BENF

$\begin{array}{llll}\text { le-tothom-neni } & \text { na } & \text { 'e } & \text { eatatiskova } \\ \text { hit-fight-BENF } & \text { ART } & \text { DEM } & \text { person }\end{array}$
'She suddenly attacked the man and fought him.' (op.cit.2)
b. m-oh-cu aha'o mi-hcihci ho
ACTF-PST-PERF sudden-ACTF ACTF-teethbare \&

$\begin{array}{lll}\text { mi-se'u } & \text { to } & \text { t'ni } \\ \text { ACTF-grimace } & \text { LOC } & \text { cliff (op.cit.6) }\end{array}$
'Suddenly she bared her teeth and grimaced towards the cliff.'

Thus, all Formosan branches of Austronesian display this phenomenon to a certain extent. The facts in Formosan languages can be summarized as in (28).
(28) - Atayalic: full voice on ADV, default on V
- Paiwanic: full voice on ADV, default on V
- Tsouic: defective voice agreement on ADV, full voice on $\mathrm{V}$

Outside Formosa, the phenomenon is rarer, although not non-existent. In Tagalog, only the linear order and the occurrence of the ligature na / nang between the manner adverb and the remainder of the clause points to what may be predicative status for the manner adverb.
a. mabilisna naglakad si Pedro
quick LIG walk NOM Pedro
'Pedro walked quickly' (Schachter \& Otanes 1972: op.cit. 436)
b. naglakad si Pedro nang mabilis
walk NOM Pedro LIG quick
'Pedro walked quickly' (Schachter \& Otanes 1972: 436)

However, in Tukang Besi (Mark Donohue, p.c.) the perfective morpheme mo 'PRF' which is prototypically attached to verbs (30a), intstead attaches to an adverb of a certain class if one is present $(30 \mathrm{~b}, \mathrm{c})$. Attaching it to the main verb instead of to the adverb varies from ungrammatical to marginal $(30 \mathrm{~d}, \mathrm{e})$, whereas 
attaching it to both is ungrammatical (30f, g). This is irrespective of the possible verbal status of the adverb, since it holds even for adverbs which do not allow predication in their own right $(30 \mathrm{~h})$.
(30) a. no-tinti $=$ mo
3SG-run-PRF
'S/he ran.'
c. po'oli=mo no-tinti
already $=$ PRF $3 \mathrm{SG}$-run
'S/he has already run.'
e. ?po'oli no-tinti=mo
already 3SG-run=PRF
g. *po'oli=mo no-tinti $=$ mo
already $=\mathrm{PRF} \quad 3 \mathrm{SG}-\mathrm{run}=\mathrm{PRF}$
b. no-menti'i=mo no-tinti 3SG-quickly=PRF 3SG-run 'S/he ran quickly.'
d. ?*no-menti'i no-tinti=mo
3SG-quickly 3SG-run-PRF
f. ?*no-menti'i=mo no-tinti=mo
3SG-quickly=PRF 3 SG-run=PRF
h. *no-po'oli
3SG-already

Admittedly, the categories which are realized on the adverb are not the same in Tukang Besi (perfective) and Formosan languages (voice), but the existence of the phenomenon in a relatively wide genetic space among Austronesian languages may be an indication that it is part of the linguistic inheritance of Austronesian languages, despite the fact that most Austronesian languages have lost the morphological desinences relating to it. Under such an assumption, the ordering of adverbs in Malgasy falls out naturally as the consequence of a distinction between two kinds of heads which in itself serves to permit the cooccurrence of head-raising and predicate raising in the same language.

\section{Conclusion}

To summarize, we have argued that the problems of adverb ordering in Malagasy and other typologically similar VOS languages can be solved by means of a classification of heads into two major categories for which we have morphosyntactic evidence in at least some Austronesian languages, and that it is not necesary to make use of a morphosyntactically unmotivated distinction between XP vs. $\mathrm{X}^{\circ}$ status for adverbs to block intraposition in either Seediq or Malagasy in order to derive the correct linear order. The exact nature of $\mathrm{X}$-heads and $\mathrm{Y}$-heads and their possible connection with an $\mathrm{A} / \mathrm{A}$ '-distinction as outlined by Carnie, Harley \& Pratt (2000) is an issue which we defer to future research.

ACKNOWLEDGEMENT: This paper is the result of fieldwork conducted in taiwan in 1993, 1995 and 1998. I gratefully acknowledge financial support from the Swedish Research Council for the Humanities and Social Sciences, The Lundberg Ido Foundation, The Bank of Sweden Tercentenary Fund and Vetenskapssocieteten, which made this research possible. I am also grateful to the audience at AFLA XI in Berlin, 2004, for valuable comments. The paper has been substantially improved by comments from and discussion with Edith Aldridge, Henry Yungli Chang, Sandra Chung, Mark Donohue, Sheila Dooley Collberg, Hans-Martin Gärtner, David Gil, Nelleke Goudswaard, Paul Law, Peter Sells, Lisa Travis, Dylan Wei-Tien Tsai and Jordan Zlatev. Naturally, my deepest vote of thanks goes to my principal Seediq consultant and friend Temi Nawi Tseng of Puli, Taiwan. Needless to say, any mistakes are mine and mine alone. 


\section{Endnotes}

1. [si] and [s] are idiolectal variants of sa.

2. Although it is likely that it derives etymologically from a matrix clause taking the remainder of the utterance as its complement.

3. The question might be posed whether a checking relation must necessarily be local. However, in a language like English, it appears to be the presence of a Neg head between $\mathrm{V}$ and $\mathrm{T}$ which forces do-insertion to realize tense, whereas nonlocal checking could lead to clauses like '*He not drinks beer.'

4. Given this fact, Sandra Chung (p.c.) has suggested an alternative analysis, following Chang (2004), which dispenses with the $\mathrm{X} / \mathrm{Y}$ distinction, instead reducing similar facts in the Formosan language Kavalan to a generalization that adverbial meanings are grammatically encoded as verbs in languages of this type, and that lexical verbs behave in a different way from other types of head. While it is clear that manner adverbs in languages such as Seediq and Kavalan are verbs in the very relevant sense of being able to bear verbal morphology, as well as possibly expressing the primary semantic predication in the clause (as discussed in Holmer 2002), this does not allow us to do away with $X$-heads altogether: over and above manner adverbs / verbs, X-heads include tense markers, negators and some (but not all) subordinators: these can hardly be considered to be verbs under any analysis, yet they share the typical $\mathrm{X}$-head trait of being involved in head movement and thereby being realized preverbally. Further, while the verbal status of manner adverbs is clear in a language like Seediq where these elements can bear verbal morphology, it is less clear in a language like Malagasy, where preverbal adverbs do not display any traits typical of lexical verbs. At the same time, the present analysis allows us to account for the largely identical adverb ordering in both Seediq and Malagasy at the same time, making use of exactly the same mechanism. This generalization would be lost under a lexical approach. Instead, I favour the idea that X-heads which have lexical content are indistinguishable from verbs by virtue of the very fact that they have both lexical content and verbal morphology, i.e. that they are verbs in a very real sense, but as a consequence of other properties rather than as a primitive.

\section{References}

Aldridge, Edith. 2002. Nominalization and WH-movement in Seediq and Tagalog. Language and Linguistics 3.2: 393-426. Taipei: Academia Sinica

Borsley, Robert, Maria-Luisa Rivero \& Janig Stephens. 1996. Long Head Movement in Breton. In Ian Roberts \& Robert Borsley (eds). The syntax of the Celtic languages. Cambrudge: CUP. 53-74

Carnie, Andrew, Harley, Heidi \& Pyatt, Elizabeth. 2000. VSO order as raising out of IP? Some evidence from Old Irish. In Andrew Carnie \& Eithne Guilfoyle (eds). The syntax of verb-initial languages. Oxford: OUP. 39-59

Chang Yung-Li. 2004. The guest playing host: Modifiers as matrix verbs in Kavalan. Paper presented at AFLA XI, Berlin, April 2004.

Cinque, Guglielmo. 1997. Adverbs and functional heads. A cross-linguistic perspective. Oxford: Oxford University Press 
Holmer, Arthur. forthcoming 2004. Seediq - antisymmetry and final particles in a Formosan VOS language. Andrew Carnie, Sheila Dooley Collberg \& Heidi Harley (eds). Verb First: Papers on the Syntax of Verb Initial Languages. John Benjamins.

Huang. Lillian. 1993. A study of Atayal syntax. Taipei: Crane Publishing Co. Huang, Lillian. 1995. A study of Mayrinax syntax. Taipei: Crane Publishing Co.

Jeng, Heng-hsiung. 1977. Topic and focus in Bunun. (Inst of History and Philology, Academia Sinica Special Publication no. 72). Taipei: Academia Sinica

Massam, Diane. 2000. VSO and VOS. Aspects of Niuean word order. In Andrew Carnie \& Eithne Guilfoyle (eds). The syntax of verb-initial languages. Oxford: OUP. 97-116

Pearson, Matt. 1998. Predicate raising and VOS order in Malagasy. UCLA Occasional Papers in Linguistics 20: 94-110

Rackowski, Andrea \& Travis, Lisa. 2000. V-initial languages: X or XP movement and adverbial placement. In Andrew Carnie \& Eithne Guilfoyle (eds). The syntax of verb-initial languages. Oxford: OUP. 117-141.

Shlonsky, Ur. 2003. The form of Semitic noun phrases. to appear in Lingua.

Szakos, Jószef. 1994. Die Sprache der Cou. Untersuchungen zur Synchronie einer austronesischen Sprache auf Taiwan. (2. Teil: Texte und lexikalische Analyse). PhD thesis. Friedrich-Wilhelms-Universität, Bonn.

Schachter, Paul \& Fe Otanes. 1972. Tagalog reference grammar. Berkeley: University of California Press.

Arthur Holmer

Lund University

Dept of Linguistics and Phonetics

Centre for Languages and Literature

Box 201, SE-221 00 Lund

Sweden

arthur.holmer@ling.lu.se 